\title{
Commentary on aptamers for virus research
}

\author{
Yasuyuki Miyazaki ${ }^{1 *}$ and Mikako Fujita ${ }^{2}$ \\ 1 Department of Microbiology, Institute of Health Biosciences, The University of Tokushima Graduate School, Tokushima, Japan \\ 2 Research Institute for Drug Discovery, School of Pharmacy, Kumamoto University, Kumamoto, Japan \\ ${ }^{*}$ Correspondence: ymiyazaki@basic.med.tokushima-u.ac.jp
}

\section{A commentary on}

Aptamers in virology: recent advances and challenges

by Binning, J. M., Leung, D. W., and Amarasinghe, G. K. (2012). Front. Microbiol. 3:29. doi: 10.3389/fmicb.2012.00029

Aptamers are oligonucleotide ligands that form unique secondary and tertiary structures, such as stem loops, kinks, bulges, and pseudoknots. Each aptamer exhibits a unique interface, through its structure, that specifically recognizes the target molecule. In fact, the target recognition of aptamers is highly specific, and it has been reported that an aptamer is able to discriminate between closely related isoforms or different conformational states of the same molecule (Conrad and Ellington, 1996; Proske et al., 2002).

Aptamers are often compared with antibodies due to their high specificity and affinity to the targets; however, they have some advantages over antibodies. For instance, antibodies require animals to be generated. Aptamers are generated by in vitro chemical synthesis, which enables chemical modification to control their stability or to add fluorescent dye on demand. Moreover, antibodies basically function in extracellular regions, whereas aptamers are easily introduced into the intra-cellular compartment by transfection. Loss-of-function technologies such as gene knockout, antisense oligonucleotide, and RNA interference (RNAi) are actively utilized for gene targeting. These aim to address the function of a target product through gene inactivation at the genomic or transcriptional level. Proteins often have multiple functions and work as part of multiprotein complex. It is often difficult to validate the functional relevance of the proteins by deletion at the genomic or transcriptional level. Aptamers are applicable to these proteins since aptamers can directly bind target proteins. As proteinbased target validation reagents other than antibodies, peptides derived from phage display libraries are available. These peptides, however, require in vivo production, and in part, exhibit poor specificity to the target molecules, which remains to be overcome for general application. Thus, aptamers have some advantages over other technologies currently used, and have potential for a broad range of application, such as diagnostic, therapeutic, and basic research (Figure 1).

Binning et al. (2012) summarized the recent developments and future prospects of aptamers in the virus research field. Early and reliable detection of pathogens is important for the successful treatment and prevention of virus epidemics. As a diagnostic tool, aptamers have ideal properties, such as (1) highly specific and tight affinity to target molecule, (2) facilitation of modification, and (3) stability. Due to these advantages, aptamers are being actively investigated as a diagnostic tool. In addition, aptamers can be coupled to existing biosensors, achieving very high sensitivity (Zhou et al., 2010). Aptamers can also be exploited as therapeutic reagents. As mentioned above, aptamers can be located in both extra- and intra-cellular regions, where they are capable of targeting any viral components. In fact, aptamers have been reported to work in various viral replication steps, such as entry, transcription, translation, and genome packaging (Binning et al., 2012). Furthermore, aptamers exhibit little or no immunogenicity and toxicity. Since oligonucleotides, especially RNAs, are readily broken down by nucleases in organisms, aptamers have to evade from attack of nucleases for therapeutic use. $2^{\prime}$-Fluoropyrimidine modification, $2^{\prime}$-O-methyl nucleotides, or $3^{\prime}$ end cap modification has been developed to achieve resistance to nucleases (Keefe and Cload, 2008). Thus, aptamers are potent therapeutic reagents. In addition, aptamers can be an excellent tool for drug discovery, and a competitive screening method has been developed (Green et al., 2001). A large pool of chemical compounds is screened against an aptamer/target complex. Only a chemical compound capable of binding the target molecule with equivalent or higher affinity than the aptamer/target can displace the aptamer from the target molecule. This aptamer approach enables high-throughput screening of potent drug candidates. Of note, the aptamer approach is applicable even if the natural ligand/ substrate is unknown. Aptamers can also be a useful tool for basic research by specifically targeting and disrupting the functions of viral or host protein involved in viral replications. For example, Binning et al. (2012) described an aptamer targeting Tax of human T-cell leukemia virus and those targeting $\mathrm{NC}$ of human immunodeficiency virus. Thus, aptamers can provide invaluable insight into viral replication.

Over two decades have passed since the initial description of a screening method of aptamers, so called systematic evolution of ligands by exponential enrichment (SELEX; Ellington and Szostak, 1990; Tuerk and Gold, 1990) and applications using aptamers have become more sophisticated and are increasing. Now is a good time for all researchers in the virus research field to consider the use of aptamers. 


\section{(A) Diagnostics}

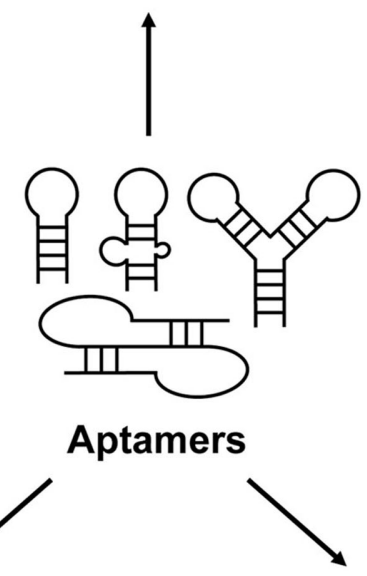

\section{(B) Therapeutics}

FIGURE 1 | Possible applications of aptamers in virus research. (A) Aptamers as diagnostic tools. Aptamers exhibit highly specific recognition with very tight affinity $\left(K_{\mathrm{d}}<1 \mathrm{nM}\right)$ to the target molecules. Aptamer-based detection assays are expected to reach lower detection limits than conventional antibody-based detection assays such as ELISA. (B) Aptamers as therapeutics. Due to specific and tight affinity to the target molecules, and low or no immunogenicity and toxicity, aptamers are expected to be

\section{(C) Basic research}

effective therapeutic reagents. Moreover, aptamers are capable of existing in extra- and intra-cellular regions, indicating that any viral components can be targeted by aptamers. (C) Aptamers as a basic research tool. Antibodies or peptides derived from phage display libraries are generally used for protein-based target validation. Aptamers have some advantages over these methods because of their short development time, in vitro synthesis, and high specificity.

\section{REFERENCES}

Binning,J.K.,Leung, D.W., and Amarasinghe, G. K. (2012). Aptamers in virology: recent advances and challenges. Front. Microbiol. 3:29. doi: 10.3389/fmicb.2012.00029

Conrad, R., and Ellington, A. D. (1996). Detecting immobilized protein kinase $\mathrm{C}$ isozymes with RNA aptamers. Anal. Biochem. 242, 261-265.

Ellington, A. D., and Szostak, J. W. (1990). In vitro selection of RNA molecules that bind specific ligands. Nature 346, 818-822.

Green, L. S., Bell, C., and Janjic, N. (2001). Aptamers as reagents for high-throughput screening. BioTechniques 30, 1094-1100.
Keefe, A. D., and Cload, S. T. (2008). SELEX with modified nucleotides. Curr. Opin. Chem. Biol. 12, 448-456. Proske, D., Höfliger, M., Söll, R. M., Beck-Sickinger, A. G., and Famulok, M. (2002). A Y2 receptor mimetic aptamer directed against neuropeptide Y. J. Biol. Chem. 277, 11416-11422.

Tuerk, C., and Gold, L. (1990). Systematic evolution of ligands by exponential enrichment: RNA ligands to bacteriophage T4 DNA polymerase. Science 249 , 505-510.

Zhou, J., Battig, M. R., and Wang, Y. (2010). Aptamerbased molecular recognition for biosensor development. Anal. Bioanal. Chem. 398, 2471-2480.
Received: 26 January 2012; accepted: 31 January 2012; published online: 14 February 2012.

Citation: Miyazaki Y and Fujita M (2012) Commentary on aptamers for virus research. Front. Microbio. 3:52. doi: 10.3389/fmicb.2012.00052

This article was submitted to Frontiers in Virology, a specialty of Frontiers in Microbiology.

Copyright $\odot 2012$ Miyazaki and Fujita. This is an openaccess article distributed under the terms of the Creative Commons Attribution Non Commercial License, which permits non-commercial use, distribution, and reproduction in other forums, provided the original authors and source are credited. 